\title{
A systemic approach to tackling ocean plastic debris
}

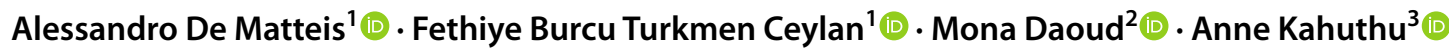

Accepted: 1 September 2021 / Published online: 29 September 2021

(c) The Author(s) 2021

\begin{abstract}
Growing evidence of the prevalence of plastics in the oceanic environment is causing increasing concern. In this study we consider the possible impact of major changes to the supply and consumption of plastics. While we recognize that tackling the problem of plastic debris in the ocean calls for integrated solutions, our analysis contributes to filling the gap in knowledge about the effectiveness of intervention strategies. Our results find that strategies addressing plastics demand have a greater impact than those focussing on plastics supply. However, only measures aimed at plastics supply are effective in the short run. These considerations can help to inspire the prioritization of intervention strategies and to contribute to the design of integrated interventions aimed at tackling the problem of marine plastic debris through a systemic approach.
\end{abstract}

Keywords Plastic debris · Marine environment · New plastics economy

\section{Introduction}

Plastics manufacturing is continuously on the rise. Almost half of the over 300 million MTs of plastics produced annually worldwide is for single-use purposes. ${ }^{1}$ By its nature, the use of single-use plastics is quite short, but on the contrary it is destined to stay on the planet for several hundred years. These few-apparently contradictory-considerations remark our current incapacity to find a consistent solution to reconciling our need for plastics with our inability to handle plastic waste.

In particular, the infamous garbage patches on the surface of oceanic gyres are evidence of the unprecedented scale of one of the trickiest forms of plastic pollution. While the

Alessandro De Matteis

a.de-matteis@uea.ac.uk; dematteis.ale@gmail.com

Fethiye Burcu Turkmen Ceylan

f.turkmen@uea.ac.uk

Mona Daoud

mdaoud@cedare.int

Anne Kahuthu

kahuthu@yahoo.com

1 School of International Development, University of East Anglia, Norwich NR4 7TJ, UK

2 Centre for Environment and Development for the Arab Region and Europe, Cairo, Egypt

3 Independent Environmental Consultant, Nairobi, Kenya nature and scale of ocean plastic pollution are under investigation, there is some general agreement about the unsustainability of the current patterns of plastics production and use. Having said that, it remains unclear what works better to contain ocean plastic debris: measures aimed at containing the supply of plastics, or measures aimed at improving their use? There seems to be no clear answer to this question yet. Reducing the supply of plastics seems a simplistic answer. In fact, while it can contribute to containing the escalation of the problem, its marginal impact may be inadequate in the short term in view of the stock of marine plastic debris already in place. On the other end, a few studies emphasize the importance of public awareness and behavioural change in influencing pro-environmental concern and behaviour. Initiatives on both the demand and the supply side are required: both changes in our cultural attitudes to plastics and changes to production and waste management practices will greatly influence future projections (Worm et al., 2017). Taking this perspective, we compare the expected effectiveness of separate approaches. After considering various aspects of the plastics economy and plastic pollution, we make use of real data to assess the effectiveness of possible strategies.

\footnotetext{
${ }^{1}$ See www.unep.org/interactive/beat-plastic-pollution/
} 


\section{Literature review}

The supply of plastics has increased exponentially since the middle of the last century, substantially outpacing that of most other manufactured materials (Geyer et al., 2017). Its importance in the economy has also grown consistently, with an estimated multiplier effect of 2.4 in GDP and 3 in employment. $^{2}$

However, the intense consumption of plastic products is leading to a visible accumulation of plastic debris (Barnes et al., 2009) caused by a combination of factors: (a) the durability of plastics; (b) their low cost, and (c) the current plastics production and use pattern, which is based on the linear "take, make, use and dispose" model. While (a) and (b) support the preference for plastics as a substitute for other manufactured materials, the linear model is unsustainable in the long term and is a primary driver of natural resource depletion, waste, environmental degradation and climate change, and has adverse effects on human health (Barra et al., 2018). These considerations have recently led to proposals for a series of measures to establishing a "new plastics economy" reflecting the principles of the circular economy and with the aim of minimizing waste and keeping materials in the economy through solutions that will help to close the material loop. While initial steps have been moved in such a direction, so far, prevailing recycling rates remain very low, showing that there is a long way to go. ${ }^{3,4}$

In the meantime the quantity of plastic debris is expected to increase further. The case of marine plastic debris is of particular concern: it is estimated that $1.5-4 \%$ of global plastics production ends up in the oceans every year (Jambeck et al., 2015), mainly as a result of poor waste management infrastructure and practices combined with irresponsible attitudes to the use and disposal of plastics. Reports of plastic pollution in the ocean first appeared in the scientific literature in the early 1970s, yet almost half a century later there are no rigorous estimates of the amount and origin of plastic

\footnotetext{
2 In 2015 the European plastics industry reported a turnover of more than 340 billion Euros and directly employs over 1.5 billion people (PlasticsEurope 2016). Similarly, in 2015 the USA plastics industry sustained 954,000 jobs while making a revenue of USD 418 billion (Plastics Industry Association 2016).

${ }^{3}$ For instance, the EU requires for its Member States to adopt measures to cut the consumption of plastic bags and other single-use plastic items (EC 2018)

${ }^{4}$ Global plastics recycling is estimated to cover only about $9 \%$ of the 6300 MTs of plastic waste generated between 1950 and 2015 (Geyer et al., 2017). India has probably the highest plastics recycling rate, with estimates ranging from 47 to $60 \%$. In the EU only approximately $30 \%$ of 25 MTs of post-consumer plastic waste was recycled in 2014; China had a recycling rate of $22 \%$ in 2013 ; and only $9.5 \%$ of plastics entering the US municipal solid waste stream were recycled in 2014 (Barra et al., 2018).
}

debris entering the marine environment (Jambeck et al., 2015) and comparable long-term environmental datasets on plastic debris are few and far between (Bergmann et al., 2017; Law 2017). Thompson et al. (2004) remarked a significant increase in microplastics from 1960-70 to 1980-90 but could find no significant trend between the 1980s and 1990s. While other studies of open ocean plastic datasets have been unable to find any increase since the 1990s (Law et al., 2010, 2014; Còzar 2014), Ostle et al. (2019) have recently highlighted a significant increase in the volume of plastic debris in the open ocean in recent decades.

Whichever the case, it is clear that plastics-and hence ocean plastic debris-are here to stay. The growth of plastics in the waste stream is only expected to increase, and according to Hoornweg et al. (2013) global "peak waste" will not be reached before 2100. Jambeck et al. (2015) predict that without significant improvements of waste management infrastructure the cumulative quantity of plastic waste available to enter the ocean from land will increase by an order of magnitude by 2025 . The fact that sixteen of the top twenty plastics producers are middle-income countries, many of which are experiencing fast economic growth but lack waste management infrastructure is not encouraging (Jambeck et al., 2015). Even if economically justifiable, the pervasive use of plastics due to their low cost and high durability have made this material the perfect embodiment of consumerism and of the consumerist approach. The widespread use of plastics for the production of single-use items is a clear example of the short-sightedness of this approach.

The problem of ocean plastic debris is ubiquitous. High concentrations of floating plastic debris have been found in the Pacific (e.g., Wong et al., 1974; Shaw et al., 1979; Day et al., 1990) and the Atlantic Ocean. Ostle et al. (2019) report that macroplastic debris is found throughout the North Atlantic, with more entanglements occurring in the area of high-density shipping routes, supporting the assumption of a link between plastic debris and human activity (Niaounakis, 2017). Along the same lines, the impact of anthropogenic pollution is confirmed by the high occurrence of entanglements and plastic debris concentrated near coastal and riverine input areas (Còzar 2014; Jambeck 2015; Niaounakis, 2017). Lebreton et al. (2017) estimate that between 1.15 and 2.41 million tonnes of plastic waste flow into the oceans from rivers annually. ${ }^{5}$

The weathering of plastic debris causes its fragmentation into particles that even small marine invertebrates may

\footnotetext{
${ }^{5}$ Lebreton et al. (2017) found plastics production per country a major driver of the flow of plastic waste into the oceans together with population density and waste management.
} 
ingest (Goldstein et al., 2013) hence contaminating the food chain. Their small size renders them untraceable to their source and extremely difficult to remove from open ocean environments. ${ }^{6}$ In such conditions the most effective mitigation strategy is to reduce the input (Jambeck 2015). One of the key strategies for achieving this target is the use of waste as a resource, evolving towards a circular economy: in other words persuading society to stop thinking of plastics as a waste and to see them as a renewable resource that needs to be disposed of correctly. At the same time, discouraging the non-essential production and unnecessary consumption or use of plastics can play a critical role in containing their leakage into the environment. In some cases the latter strategy is seen as the first priority (Barra et al., 2018). At this stage, the question becomes the identification of the most effective strategy for reducing inputs.

That is easier said than done. Plastics are present either directly or indirectly in almost every aspect of our daily life. Therefore, designing a comprehensive intervention strategy about plastics and plastic waste is not an easy task. For instance, let's take the case of single-use plastics, which are responsible for the largest share of marine plastic pollution. Single-use plastics create negative externalities, highlighting a case for a tax on producers to help correct the market failure. However, since many consumers have a strong bias towards single-use plastic items, the demand for plastic products may be price inelastic, which means that the tax is ineffective as producers will manage to pass most of the extra cost on to consumers. At the end of the day, the more inelastic the demand for plastic products, the larger the share of the indirect tax that can be passed on to the final consumer and therefore the less effective the tax. In this case an eventual change of consumers' behaviour can make the difference. In this regard the plastic bag tax is a good case in point. In some cases it is seen as a success (e.g., Martinho et al. 2017), but other studies highlight how a share of the plastics reduction imposed by the plastic bag tax is lost due to consumption shifting towards unregulated trash bags. Of course, consumers' sensibility towards the plastic waste problem contributes to explain the different performance of similar policies, ${ }^{7}$ but the consideration above remarks how an integrated systemic approach is required when designing a regulating system in order to avoid leakage effects. In such conditions, while part of the literature considers public awareness and behavioural change among plastics

\footnotetext{
${ }^{6}$ Recent studies have documented the plastic "fallout" from the garbage patches into the underlying deep sea providing evidence of the massive size of the problem (Egger et al., 2020).

7 Needless to say, in this regard it is interesting to consider how the average number of plastic bags used by an individual ranges quite widely: e.g., it is estimated to be around four units in a year in Denmark and about one unit per day in the United States (Parker 2019).
}

users as the most important way forward (e.g., UNEP 2016; Veiga et al., 2016; Pahls et al., 2017; Löhr et al., 2017; Jefferson 2019; Locritani et al., 2019), other studies remark the need to look at the larger picture. A growing body of literature questions the adequacy of the currently proposed policy responses to the problem of plastic pollution (e.g., Borrelle et al., 2017; Xanthos and Walker 2017; Dauvergne 2018; Nielsen et al., 2019; van Veelen and Hasselbalch 2020) remarking that while on one side the market-based instruments have done little to curb plastic pollution, on the other side the fragmented nature of current plastics governance allows the industry actors to deflect responsibility. For instance, the Extended Producer Responsibility (EPR) scheme in the EU has increased the recycling rate of plastic packaging, however it fails to encourage industries to explore the full mitigation potential of plastic pollution reduction. It is remarked how higher compliance fees for plastic producers as well as higher environmental standards of plastic products could help to motivate producers to adopt a more eco-friendly business attitude. Likewise, steps towards the harmonization of EPR regulation among EU member states can lead to reductions of plastic pollution (Jia et al., 2019).

At a higher level, a few transnational policy initiatives have proposed some attempts to move towards a regulatory framework of plastics, mainly inspired by a circular economy approach, ${ }^{8}$ or aimed at tightening the conditions of global trade in plastic waste. ${ }^{9}$ In order to do so, further steps are required to develop an integrated perspective that investigates the politics of plastics throughout the entire life cycle: from production, through consumption, to waste and pollution (Borrelle et al., 2017; Nielsen et al., 2019).

In the meantime, a concern that is often raised about the effectiveness of policy measures related to plastics and plastic waste is the wide knowledge gap which is still there. In the following sections we contribute to fill such knowledge gap; we make use of real data and try to answer the simple question "what works better to contain ocean plastic debris: measures aimed at containing plastics supply or measures aimed at improving its use?"

\footnotetext{
${ }^{8}$ See, in particular, the EU Plastic Strategy (European Commission 2018) and the New Plastic Strategy Global Commitment (Ellen MacArthur Foundation 2016, 2017).

9 The Basel convention, adopted in 1989 with the aim of reducing the transfer of hazardous waste between nations, was amended in 2019 to include plastic waste.
} 


\section{Methodology}

\subsection{Systemic approach, non-linearity and model selection}

In this study we adopt a simplified systemic approach to plastics production, management and use. For simplicity we ignore all aspects of recycling and waste management to focus instead on the bulk of what constitutes the nexus of plastics supply and demand. ${ }^{10}$

As a preliminary step, we adopted a non-parametric approach to test our data for possible non-linearity. ${ }^{11}$ Besides some simple visual assessment, the non-parametric analysis allowed us to come up with some initial non-parametric kernel regressions. As this type of regression does not impose linearity and allows the model to have polynomial structures, it provides a valid way of testing the linearity of the data and consequently of instructing the model selection.

Trying to explain ocean plastic debris solely by focussing on either the supply of plastics or its consumption would suffer from a lack of robustness. On the other hand, combining supply and demand in a single model can create problems of collinearity. Furthermore, it is clear that economic measures acting on supply and demand work in different ways, and therefore combining them within a single equation could create a misleading framework. Hence, a system of simultaneous equation models that can cover supply and demand together is required, as in the case of Seemingly Unrelated Regression (SUR) or Vector Auto-regression (VAR). The consideration that the VAR approach requires a condition of endogeneity among all the variables involved, a condition that is not satisfied in our case, leads us to opt for a SUR modelling approach.

SUR is a type of generalized linear regression model which assumes that the error terms of the equations are correlated, implying that there are common observable factors for all equations. SUR provides consistent and efficient parameter estimates, unlike single-equation linear regression models that provide only consistent estimates. ${ }^{12}$ We use the Breusch-Pagan test to ascertain this assumption.

\footnotetext{
${ }_{10}$ Waste management and the circular economy are expected to play a key role in improving the overall efficiency of the system; nevertheless, their relevance so far is negligible, and their contribution is not reflected in the historical dataset adopted in this study.

11 Ocean plastic debris is cumulative and the rate of its accumulation may accelerate or decelerate over time. Integrating data on recycling policies into our model could help to address this aspect of the problem. However, due to the lack of the data necessary to address this issue for the period considered in this study, we can try to tackle it by considering any possible non-linear links. In fact, if the rate of accumulation of debris changes over time, this can be only captured by a non-linear model.

12 Additional resources about SUR modelling approach can be found at https://www.stata.com/manuals/rsureg.pdf
}

Equations (1) and (2) are used for the estimation of longterm models, while Eqs. (3) and (4) are used for the estimation of short-term models.

$Y=\beta_{0}+\beta_{1} Y_{t-1}+\beta_{2} X_{2}+\beta_{3} X_{3}+u_{1}$

$Y=\delta_{0}+\delta_{1} Y_{t-1}+\delta_{2} Z_{2}+\delta_{3} Z_{3}+u_{2}$

$\Delta Y=\alpha_{0}+\alpha_{1} \Delta Y_{t-1}+\alpha_{2} \Delta X_{2}+\alpha_{3} \Delta X_{3}+u_{1, t-1}+r_{1}$

$\Delta Y=\gamma_{0}+\gamma_{1} \Delta Y_{t-1}+\gamma_{2} \Delta Z_{2}+\gamma_{3} \Delta Z_{3}+u_{2, t-1}+r_{2}$

where: $\alpha_{0,1,2,3}, \beta_{0,1,2,3}, \gamma_{0,1,2,3}, \delta_{0,1,2,3}$ are the parameters to be estimated and $u_{1,2}$ and $r_{1,2}$ are residuals with normal distribution and constant variance.

The demand function is estimated through the number of users and their income. For the estimation of the supply function we use plastics production and the cost of the main input, the price of oil. Both income and oil price are estimated in real terms.

All parameters are logarithmically transformed to reduce the effect of heterogeneity on standard errors.

To take account of the accumulation of marine plastic debris over time, a one-period lagged component of entanglements is included in the models.

\subsection{Data}

With reference to ocean plastic debris, Ostle et al. (2019) presented a dataset based on consistent records of plastics entanglements on a towed marine sampler. The records, which run from 1957 to 2016 and cover over 6.5 million nautical miles in the North Atlantic and adjacent seas, indicate a significant increase in open ocean macroplastics in recent decades. The present analysis makes use of Ostle et al.'s (2019) dataset on ocean macroplastic debris.

It goes without saying that in view of its mobility ocean plastic debris cannot be associated with any specific source country, and hence for the sake of simplicity, we assume here that the dataset provided by Ostle et al. (2019) is applicable at the global level.

Likewise, as the analysis in this study is conducted at the global level, the number of plastic users and their incomerequired for the estimation of the demand function-are proxied, respectively, by (a) the world population, and (b) the world average income per capita expressed in real terms. Both variables are sourced from the World Bank World Development Indicators (WDI).

For the estimation of the supply function, data on global plastics production were sourced from PlasticsEurope and Geyer et al. (2017) and data about oil price in real terms were sourced from WDI.

All data refer to annual series from 1970 to 2016. 
Fig. 1 Evolution of variables $(1970=100)$. Ostle et al. (2019), PlasticsEurope and Geyer et al. (2017), World Bank WDI

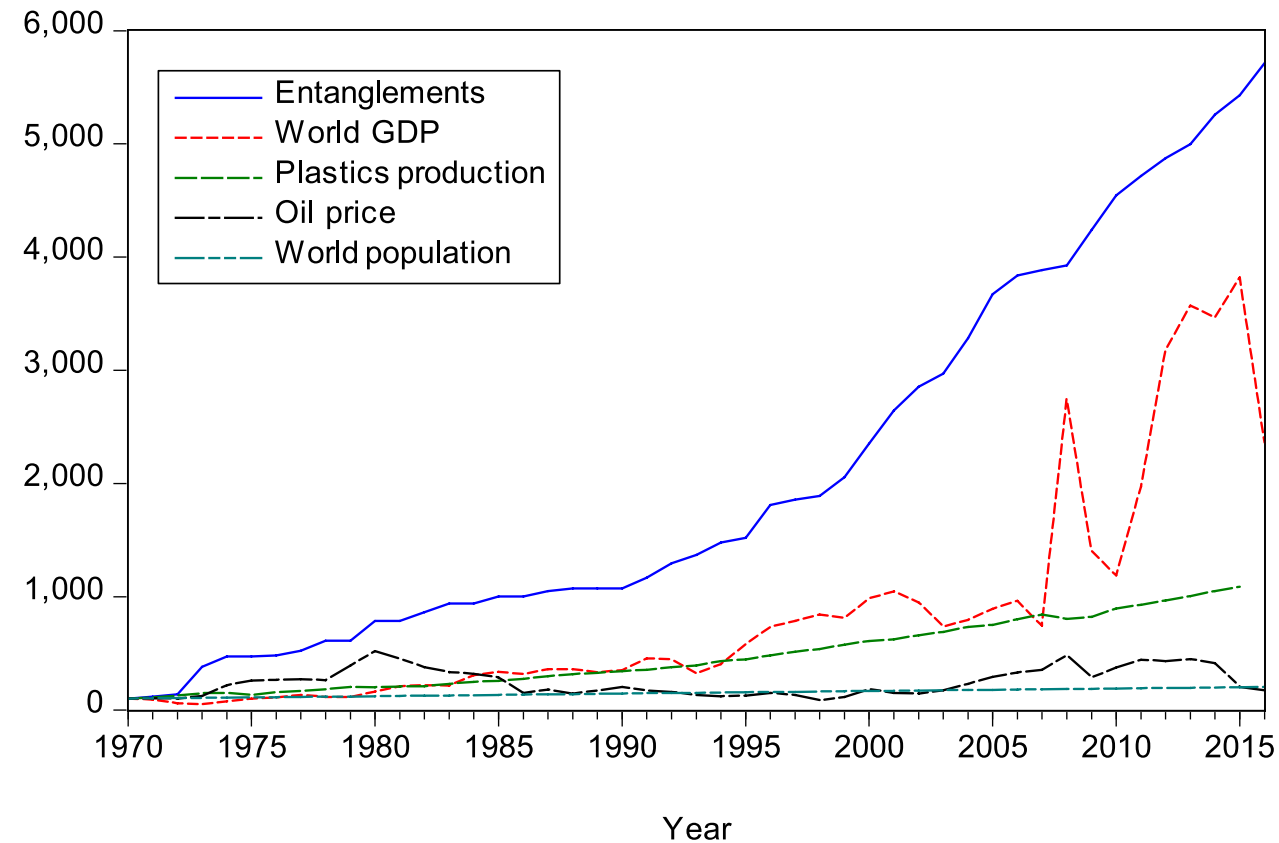

Source: Ostle et al. (2019), PlasticsEurope and Geyer et al. (2017), World Bank WDI

\section{Findings}

Figure 1 allows visual inspection of the evolution of the variables analysed in this study, highlighting the increasing trends over the period under consideration, although with very different slopes. It is important to remark that plastics production is considered here as flows to capture the new input of plastics into the economic system. Ocean plastic debris, on the other hand, is considered here as a stock, and annual data have been cumulated to take into account the very slow degradation process and consequently the long time required for plastic debris to decompose.

Figure 1 does not reveal evident patterns of non-linearity; nevertheless, to thoroughly investigate our dataset to determine whether a linear approach is capable of delivering robust results, we employ non-parametric kernel distributions. The diagrams derived from the non-parametric kernel distributions are shown in Fig. 2. The number of entanglements, taken as a measure of marine plastic debris, is shown on the horizontal $(X)$ axis and presents our dependent variable, while the parameters on the vertical $(Y)$ axis are our independent variables. The distributions reveal that the only instance of non-linearity refers to the oil price variable. Having said that, it should be noted that a considerable proportion of the oil price data has linear characteristics, this way restricting the non-linear patterns of our dataset.

A second attempt to detect any potential non-linearity in our data visually compares ordinary and orthogonal regressions run on the pairs of dependent and independent variables. Any discrepancy between the two regressions would reveal the existence of measurement errors; however, visual inspection of Fig. 3 in the Appendix highlights the general overlap of the two regression lines, with some measurement error noticeable only when a linear estimator is used for the oil price variable. This assessment supports the considerations expressed above that the use of a linear estimator does not violate the robustness of the results in a pairwise setting.

At this stage we run a non-parametric kernel regression to test our visual impression that our dataset is not exposed to significant non-linearity problems. This type of regression does not impose linearity and allows models to have polynomial structures. The results are presented in Table 1. As mentioned above, the variables were considered in a systemic fashion and therefore results are arranged under Demand and Supply. To facilitate comparison with the results presented later in this analysis, the coefficients of the lagged dependent variable are also reported in Table 1.

A rapid review of the results presented in Table 1 leads us to consider first of all that the parameter estimates of the lagged entanglements highlight the cumulative nature of ocean plastic debris. Despite the similar values of the coefficients' lagged variable in the two equations, the largest coefficient in Table 1 refers to the world population, taken here as a proxy for global demand, suggesting that global demand has larger responsibility for ocean plastic debris. This interpretation finds support in the much lower coefficient estimate for plastics production, which is expected to be among the major determinants of plastic debris on the supply side of the problem. The negative sign of the GDP 
Fig. 2 Non-parametric distributions
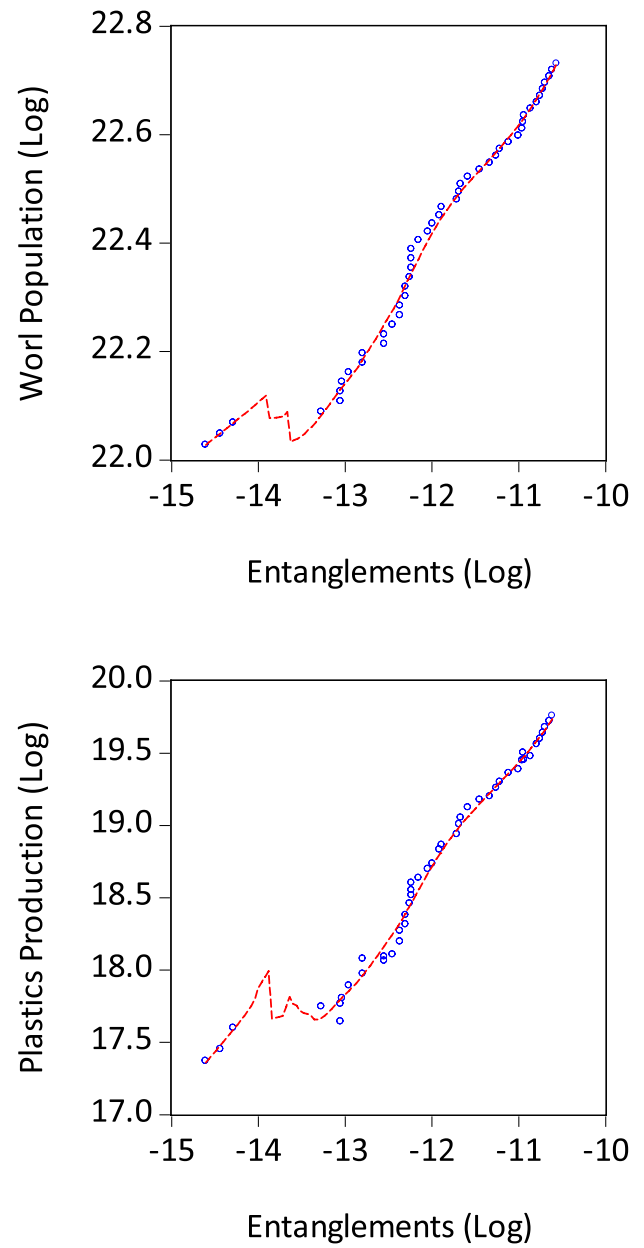
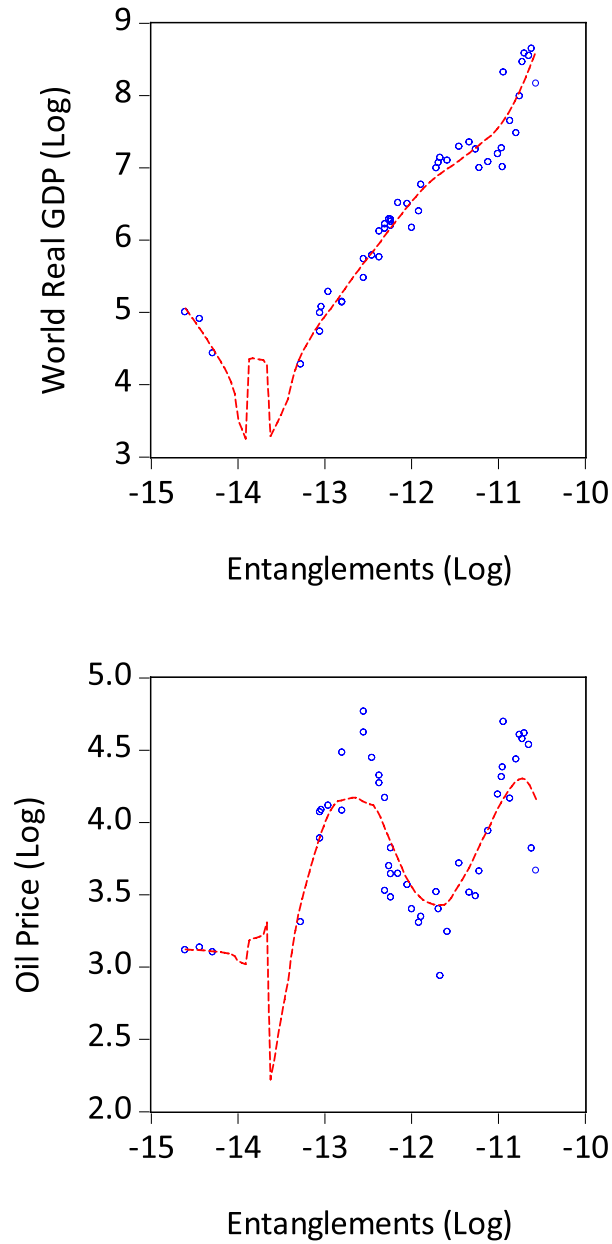

Table 1 Non-parametric regressions

\begin{tabular}{lc}
\hline \multicolumn{1}{c}{ Coeff } \\
\hline Demand & $0.693^{* * *}$ \\
Entanglments $\mathrm{t}_{\mathrm{t}-1}$ & $2.002^{* * *}$ \\
World population & -0.078 \\
Word GDP & \\
Supply & $0.657^{* * *}$ \\
Entanglements & $0.530^{* * *}$ \\
Plastics production & $0.148^{* * *}$ \\
\hline
\end{tabular}

Significance: $* p<0.10, * * p<0.05, * * * p<0.01$

coefficient supports the consideration that richer countries are likely to be more aware of the negative side effects of plastics consumption than countries with lower GDP, although the statistical significance of this argument is not supported. Lastly, the price of oil is found to be positively correlated with ocean plastic debris. This result can find a possible explanation in the reciprocal relationship between oil price and plastics supply. Nevertheless, this relationship is expected to lead to an endogeneity problem. Since it is not possible to test this assumption properly in a non-parametric equation setting, we are forced to consider more appropriate setups for this analysis. Treating supply and demand in a systemic fashion can help us to achieve more solid results, as we discuss later. Anyway, the non-parametric analysis conducted so far has allowed us to address the question raised earlier about the possible non-linearity of our variables. Earlier, the visual assessment of the kernel distributions allowed us to detect the presence of a non-linear component only with regard to the oil price variable, although we remarked its limited relevance. Contrary to our initial impression, the results presented in Table 1 highlight that the kernel regression detects only a linear component. This consideration leads us to continue the analysis through parametric linear modelling. ${ }^{13}$

\footnotetext{
13 We also tried a system of non-linear equations. Yet the number of observations and the proximity of patterns in the dependent and independent variables make this approach unfeasible as it induces multicollinearity: i.e., it reduces the rank of the equations since the number of parameters estimated exceeds the number of equations.
} 
Table 2 Long-term and short-term equations

\begin{tabular}{lcc}
\hline & Long-term (static) & Short-term (dynamic) \\
\hline Demand & & \\
Entanglments $_{\mathrm{t}-1}$ & $0.724^{* * *}$ & $0.930^{* * *}$ \\
World population & $1.175^{* * *}$ & 0.008 \\
Word GDP & -0.020 & 0.008 \\
ECT $_{\mathrm{t}-1}$ & & \\
Constant $^{2}$ & $-29.400^{* * *}$ & 0.004 \\
Adj $^{2}$ & 0.983 & 0.442 \\
Supply & & \\
Entanglments & & $0.910^{* * *}$ \\
Plastics production $_{\text {Oil price }}$ & $0.726^{* * *}$ & $0.194^{*}$ \\
ECT $_{\mathrm{t}-1}$ & $0.310^{* * *}$ & -0.003 \\
Constant & 0.003 & $-1.146^{* * *}$ \\
Adj $R^{2}$ & $-9.010^{* * *}$ & -0.005 \\
Statistics & 0.984 & 0.484 \\
Breusch-Pagan test & 0.000 & 0.000 \\
\hline
\end{tabular}

Significance: $* p<0.10, * * p<0.05, * * * p<0.01$

Table 2 reports the details of the preferred model. The first column reports the coefficient estimates of a static (long-run) model. The very high value of $\mathrm{R}^{2}$ raises some concern about the risk that our estimation can be spurious if there is no stable long-run relationship among our dependent and independent variables. On the contrary, the dynamic (short-run) model, estimated with first-differenced data, shows evidence in favour of a stable long-run relationship with plausible $\mathrm{R}^{2}$ value. Therefore, unit root tests were run to eliminate any doubt. ${ }^{14}$ Subsequently we have run the short-run SUR estimation with first-differenced data, an autoregressive component and an error-correction term, estimated as one-term lagged residuals of the static model.

Both supply and demand equations report statistically significant estimates of the autoregressive parameter, with the number of entanglements during period $t$ strongly influenced by the number of entanglements in the previous $(t-1)$ period. This confirms our assumption that entanglements are cumulative, and remarks the stability of the process of accumulation of marine plastic debris.

Among all parameter estimates, the strongest effect is observed in the demand equation with regard to the role played by the world population in the long run. This addresses the consumption side of the plastics nexus.

\footnotetext{
14 The results of the augmented Dickey-Fuller test, unreported here, have rejected the hypothesis of unit roots, this way supporting the robustness of our models.
}

Population size-as a proxy for the number of plastics users-works as a sort of multiplier, amplifying the effect induced by other variables, and therefore, its relevance can be appreciated particularly in the long run. This explains its insignificant coefficient in the short run.

Income is found to be statistically insignificant with regard to marine plastics entanglements, highlighting how the problem goes beyond any simplistic economic classification.

On the supply side, the strongest effect apart from the cumulative autoregressive component refers to plastics production. However, contrary to the case of population, plastics production plays a statistically significant effect in both the short and the long run. This finding has obvious policy implications: if marine plastic debris were to be controlled in the short run, measures aimed at plastics production would arise as the best candidate.

Moving on with the variables considered in the supply model, oil price is found to have an insignificant effect.

In both short-run models the error-correction terms are found to be statistically significant and theoretically consistent by having a negative sign. The significance of the error-correction terms shows that there is a stable level of ocean plastic debris that has been formed over a period of time. The negative sign of the ECT coefficients supports the consideration about the stability of entanglements over time, informing us that any change in the size of entanglements, induced through either supply-based or demand-based measures, is destined to vanish quickly, in less than a year. ${ }^{15}$ In particular, the greater absolute value of the ECT coefficient in the supply equation implies that the effects of a supply shock will die out slightly faster than those induced by a demand shock. This result provides evidence that the marine plastic debris linked to the supply side of the plastics supply-demand nexus is more rigid and can restore its longterm path faster than the debris linked to the demand side of the nexus.

Overall, both plastics supply and demand play a significant role in contributing to ocean plastic debris, although the former seems to have an immediate impact on the number of entanglements, while the impact of the latter seems to be significant only in the long term.

Finally, the results of the Breusch-Pagan test remark that a systemic approach that deals with supply and demand simultaneously is needed to effectively tackle the problem of marine plastic debris.

\footnotetext{
15 The coefficient of the ECT provides a measure of the speed of adjustment; in other words the expression $1 /|\mathrm{ECT}|$ measures the time required by the size of entanglements to return to a balanced condition after a shock. In this case the adjustment time is estimated to be between 10 and 11 months with regard to both supply- and demandinduced shocks.
} 


\section{Discussion and conclusions}

Plastics is one of the world's greatest industrial innovations, but the sheer scale of its production and poor disposal practices are resulting in growing adverse effects on human health and the environment. In particular, the increasing presence and concentration of plastics in the oceans is raising alarm signals about the health of the global marine environment.

This study has addressed this problem via two different methodological approaches. The results obtained using these approaches generally support each other, confirming the robustness of our findings. The coefficient estimates obtained from the two approaches have the same sign and are of similar size, implying that the different methodologies have captured the same direction of the relationship between the variables considered as well as the intensity of these relationships.

Our results provide evidence of a steadily increasing accumulation of ocean plastic debris. This is particularly alarming considering that this process of accumulation is occurring despite ongoing recycling practices and other initiatives to contain the problem.

One very important finding is the appropriateness of the systemic approach we adopted to conduct this analysis. This finding highlights the fact that no single solution will stop marine plastic pollution. The solution is likely to be found in a combination of measures to reduce the input of plastics into the marine environment. More generally, a transition towards more sustainable ways of both production and consumption is required. The circular economy approach is well placed to serve this purpose through the promotion of a production and consumption model designed to be restorative and regenerative to ensure that the value of products, materials and resources is maintained in the economy at the highest utility and value for as long as possible, while minimizing waste generation, by designing out waste and hazardous material. In the case of plastics, this means simultaneously keeping their value in the economy without allowing them to leak into the natural environment.

However, this is easier said than done. It will require a concerted effort, building on the engagement of all levels of society-primarily governments, the industry and individual consumers. A combination of legislation and the promotion of environmental consciousness will be required to achieve general awareness and a change of attitude towards the problem. It will involve a set of measures to tackle both the supply side and the demand side. On the supply side, only essential plastic products should be produced, with discouragement of non-essential production and use and the promotion of renewable and recyclable alternatives to plastics. On the demand side, education, continued research, and awareness campaigns are needed to drive users' action as well as large-scale decisions about waste management and product design.

Overall, while recognizing that integrated solutions are best at containing the escalation of ocean plastic debris, this study has assessed and compared the effectiveness of strategies aimed at either the production or the consumption of plastics. Our results demonstrate that strategies addressing the demand side of the equation appear to promise greater impact. In particular, measures aimed at demand for plastics promise to be three times as effective at curbing marine plastic debris than measures addressing plastics production. This can be partly explained by the large contribution of single-use plastics - and therefore by the (ir)responsibility of many of their users- to the problem of marine pollution.

At the same time, our results highlight how the impact of any initiative is short-lived and that the long-term balance between plastics supply, plastics demand and marine plastic debris is quickly re-established via what has become a perverse system. This consideration remarks that drastic measures are required to be able to overcome the perverse system currently in place and move towards a more sustainable balance. In particular, the different speeds with which plastics supply and demand impact the amount of marine plastic debris helps to set some priority for action: the tendency detected on the supply side to get back to long-term balance faster than that on the demand side highlights the prioritization of urgent measures on the former while providing slightly longer time to intervene on the latter.

Overall, the results of this study can help to inspire the prioritization of intervention strategies. But most of all, our findings are expected to contribute to the design of integrated interventions tackling the problem of marine plastic debris through a systemic approach. The consideration that strategies aimed at plastics consumption seem to be effective only in the long run is a reminder that drastic action is urgently required in that direction. At the same time, the consideration that measures aimed at the supply side are effective both in the short and the long run should highlight the opportunity - as well as the need-to support initiatives aimed at both containing the progression of the problem and setting up more stringent long-term strategies.

In the end, besides assessing the effectiveness of demand- and supply-based strategies, this study has highlighted how a systemic approach is required to tackle the problem of marine plastic debris.

Our finding that measures aiming at demand are expected to be more effective than supply-based ones should not allow us to forget that plastic waste is inherently consequential to plastics supply, and hence concerted effort on all sides is required. To put it euphemistically, we can quote Dauvergne (2010): "succeeding globally will require far greater change than simply increasing the number of conscientious consumers refusing plastic bags, recycling plastic bottles, or sleeping contentedly on recycled plastic pillow stuffing".

\section{Appendix}

See Fig. 3. 
Fig. 3 Linear and orthogonal regressions
I

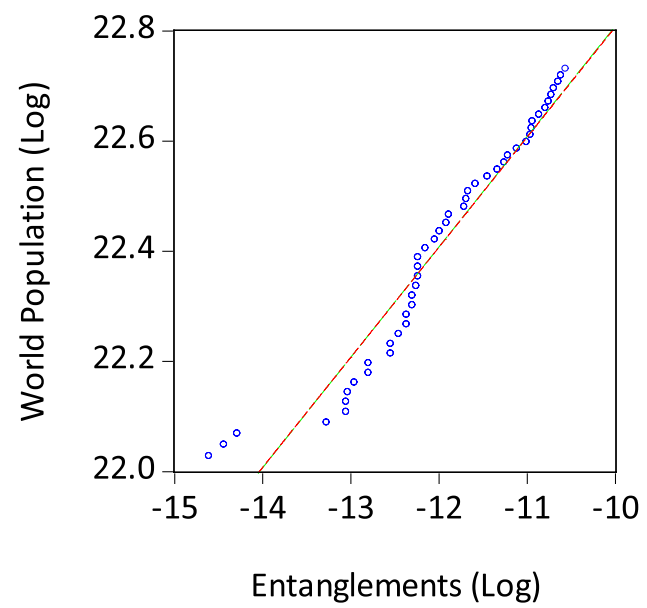

III

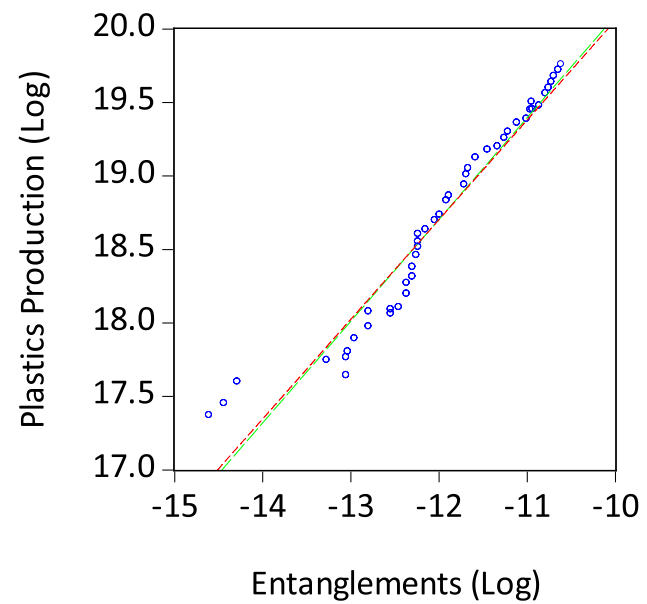

II
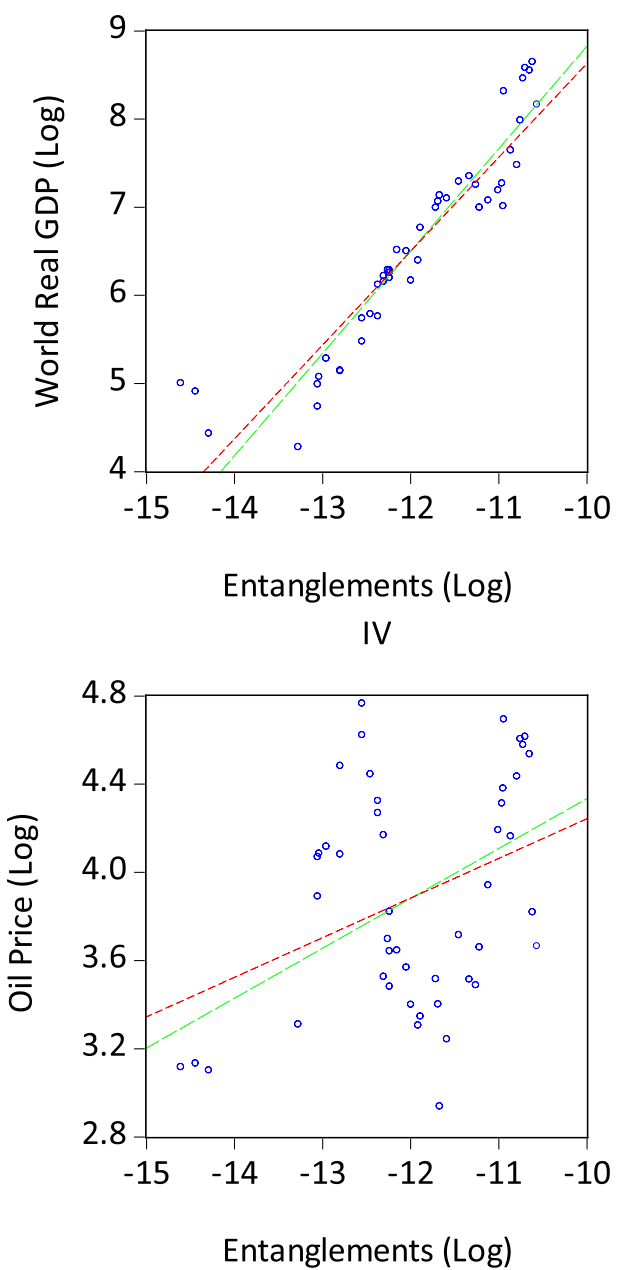

Acknowledgements The authors acknowledge with gratiture the valuable comments provided by Fariba Alamgir, by Igor Linkov and by two unknown reviewers on a previous version of this article. Usual disclaimers apply.

\section{Funding None.}

\section{Declarations}

Conflict of interest The authors declare that they have no conflict of interest.

Open Access This article is licensed under a Creative Commons Attribution 4.0 International License, which permits use, sharing, adaptation, distribution and reproduction in any medium or format, as long as you give appropriate credit to the original author(s) and the source, provide a link to the Creative Commons licence, and indicate if changes were made. The images or other third party material in this article are included in the article's Creative Commons licence, unless indicated otherwise in a credit line to the material. If material is not included in the article's Creative Commons licence and your intended use is not permitted by statutory regulation or exceeds the permitted use, you will need to obtain permission directly from the copyright holder. To view a copy of this licence, visit http://creativecommons.org/licenses/by/4.0/.

\section{References}

Barnes DKA, Galgani F, Thompson RC, Barlaz M (2009) Accumulation and fragmentation of plastic debris in global environments. Philosophical Transactions of the Royal Society B, 364.

Barra R, Sunday AL, Whaley C, Bierbaum R (2018) Plastics and the circular economy. Scientific and technical advisory panel to the global environment facility. Washington, D.C

Bergmann M, Tekman MB, Gutow L (2017) Sea change for plastic pollution. Nature 544:297

Borrelle SB, Rochman CM, Liboiron M, Bond AL, Lusher A, Bradshaw H, Provencher JF (2017) Why we need an international 
agreement on marine plastic pollution. Proc Natl Acad Sci 114(38):9994-9997

Còzar A, Echevarria F, Gonzales-Gordillo JI, Irigoien X, Ubeda B, Hernandez-Leon S, Palma AT, Navarro S, Garcia-de-Lomas J, Ruiz A, Fernandez-de-Puelles ML, Duarte CM (2014) Plastic debris in the open ocean. Proc Natl Acad Sci 111(28):10239-10244

Dauvergne P (2018) Why is the global governance of plastic failing the oceans? Glob Environ Chang 51:22-31

Dauvergne P (2010) The problem of consumption. Global Environmental Politics 10(2):1-10

Day RH, Shaw DG, Ignell SE (1990) The quantitative distribution and characteristics of nauston plastic in the North Pacific Ocean, 1985-88. In: Shomura RS, Godfrey ML (Eds) Proceedings of the 2nd International Conference on Marin Debris, (National Oceanic and Atmospheric Administration, Honolulu), pp 247-266

Egger M, Sulu-Gambari F, Lebreton L (2020) First evidence of plastic fallout from the North Pacific Garbage Patch. Sci Rep 10(1):7495

Ellen MacArthur Foundation (2017) The new plastics economy: catalysing action. Ellen MacArthur Foundation and World Economic Forum. https://www.ellenmacarthurfoundation.org/publications/ new-plastics-economy-catalysing-action

Ellen MacArthur Foundation (2016) The new plastics economy: rethinking the future of plastics. Report produced by World Economic Forum and Ellen MacArthur Foundation. https://www.ellen macarthurfoundation.org/publications/the-new-plastics-economyrethinking-the-future-of-plastics

European Commission (2018) A European Strategy for Plastics in a Circular Economy, COM/2018/028 https://eur-lex.europa.eu/ legal-content/EN/TXT/?uri=COM\%3A2018\%3A28\%3AFIN

Geyer R, Jambeck JR, Law KL (2017) Production, use, and fate of all plastics ever made. Sci Adv 3(7):e1700782

Goldstein MC, Goodwin DS (2013) Gooseneck barnacles (Lepas spp.) ingest microplastic debris in the North Pacific Subtropical Gyre. PeerJ 1:e184

Hoornweg D, Bhada-Tata P, Kennedy C (2013) Environment: waste production must peak this century. Nature 502:615-617

Jambeck JR, Geyer R, Wilcox C, Siegler TR, Perryman M, Andrady A, Narayan R, Law KL (2015) Plastic waste inputs from land into the ocean. Science 347(6223):768-771

Jefferson M (2019) Whither plastics? Petrochemicals, plastics and sustainability in a garbage-riddled world. Energy Res Soc Sci 56:101229

Jia L, Evans S, van der Linden S (2019) Motivating actions to mitigate plastic pollution. Nat Commun 10:4582

Law KL (2017) Plastics in the marine environment. Ann Rev Mar Sci 9:205-229

Law KL, Moret-Ferguson SE, Goodwin DS, Zettler ER, DeForce E, Kukulka T, Proskurowski G (2014) Distribution of surface plastic debris in the eastern pacific ocean from a 11-year data set. Environ Sci Technol 48(9):4732-4738

Law KL, Moret-Ferguson SE, Maximenko NA, Proskurowski G, Peacock EE, Hafner J, Reddy CM (2010) Plastic accumulation in the north atlantic subtropical gyre. Science 329(5996):1185-1188
Lebreton LCM, Van Der Zwet J, Damsteeg JW, Slat B, Andrady A, Reisser J (2017) River plastic emissions to the world's oceans. Nat Commun. https://doi.org/10.1038/ncomms15611

Locritani M, Merlino S, Abbate M (2019) Assessing the citizen science approach as tool to increase awareness on the marine litter problem. Mar Pollut Bull 140:320-329

Löhr A, Savelli H, Beunen R, Kalz M, Ragas A, Van Belleghem F (2017) Solutions for global marine litter pollution. Curr Opin Environ Sustain 28:90-99

Martinho G, Balaia N, Pires A (2017) The Portuguese plastic carrier bag tax: the effects on consumers' behavior. Waste Manage 61:3-12

Niaounakis M (2017) Management of marine plastic debris. William Andrew Publishing, Norwich

Nielsen TD, Hasselbalch J, Holmberg K, Stripple J (2019) Politics and the plastic crisis: a review throughout the plastic life cycle. WIREs Energy Environ 9(1):e360

Ostle C, Thompson RC, Broughton D, Gregory L, Wootton M, Johns DG (2019) The rise in ocean plastics evidenced from a 60-year time series. Nat Commun 10:1622

Pahls S, Wyles KJ, Thompson RC (2017) Channelling passion for the ocean toward plastic pollution. Nat Hum Behav 1(10):697-699

Parker, L. (2019) Plastic Bag Bans are Spreading. But Are They Truly Effective? National Geographic, 4.

Plastics Industry Association, (2016) Size and impact report. Washington, D.C.

PlasticsEurope (2016) Plastics - The facts 2016, An analysis of european plastics production, demand and waste data. Brussels

Shaw D, Day R (1979) Colour- and form-dependent loss of plastic micro-debris from the North Pacific Ocean. Mar Pollut Bull 28(1):39-43

Thompson RC, Olsen Y, Mitchell RP, Davis A, Rowland SJ, John AWG, McGonigle D, Russell AE (2004) Lost at sea: where is all the plastic? Science 304(5672):838

UNEP (2016) Marine Plastic Debris and Microplastics - Global lessons and research to inspire action and guide policy change. United Nations Environment Programme. Nairobi

Van Veelen B, Hasselbalch J (2020) Power and politics in plastics research: a critique of "Whither Plastics." Energy Research and Social Science 61:101445

Veiga JM, Vlachogianni T, Pahl S, Thompson RC, Kopke K, Doyle TH, Hartley BL, Maes T, Orthodoxou DL, Loizidou XI, Alampei I (2016) Enhancing public awareness and promoting co-responsibility for marine litter in europe: the challenge of MARLISCO. Mar Pollut Bull 102(2):309-315

Wong CS, Green DR, Cretney WJ (1974) Quantitative tar and plastic waste distributions in the Pacific Ocean. Nature 247:30-32

Worm B, Lotze HK, Jubinville I, Wilcox C, Jambeck J (2017) Plastic as a persistent marine pollutant. Ann Rev Environ Res 42:1-26

Xanthos D, Walker TR (2017) International policies to reduce plastic marine pollution from single-use plastics (plastic bags and microbeads): a review. Mar Pollut Bull 118(1-2):17-26 